\title{
New therapeutic options in myelodysplastic syndrome: literature review and single-center treatment results
}

\author{
Elena V. Morozova, Nikolai Yu. Tsvetkov, Irina O. Turtanova, Ivan S. Moiseev \\ RM Gorbacheva Research Institute of Pediatric Oncology, Hematology and Transplantation, Pavlov University, St. Petersburg, \\ Russia
}

Dr. Ivan S. Moiseev, RM Gorbacheva Research Institute of Pediatric Oncology, Hematology and Transplantation, Pavlov University, L. Tolstoy St. 6-8, 197022, St. Petersburg, Russia
Phone: +7 (921) 7961951

E-mail: moisiv@mail.ru

Citation: Morozova EV, Tsvetkov NY, Turtanova IO, Moiseev IS. New therapeutic options in myelodysplastic syndrome: literature review and single-center treatment results. Cell Ther Transplant 2021; 10(1): 24-36.

\section{Summary}

Myelodysplastic syndromes (MDS) comprise a group (continuum) of clonal hematopoietic diseases associated with high risk of transformation into acute myeloid leukemia (AML) and unfavorable prognosis. Compared to the other hematologic malignant diseases, there was only a modest improvement in survival of MDS patients over the last years. Allogeneic stem cell transplantation remains the only curative option for these patients, however, most of them are not candidates for transplantation. This review focuses on the long-term outcomes of existing therapies and novel agents that are currently tested at different stages of clinical trials. These include inhibitors of TGF $\beta$, various kinase inhibitors, and immune checkpoint inhibitors. Administration of new therapies in the patients with different pathogenetic MDS variants is discussed.

\section{Keywords}

Myelodysplastic syndrome, treatment, checkpoint inhibitors, luspatercept, glasdegib, venetoclax, IDH inhibitors.

\section{Introduction}

Myelodysplastic syndrome (MDS) represents a heterogenous group of clonal diseases caused by alterations in hematopoietic stem cells due to hereditary predisposal, along with variable somatic gene mutations, and/or abnormal epigenetic regulation, including those induced by altered microenvironment and disrupted immune surveillance [1].

Pre-leukemic features of MDS were explored since early 80 's based on atypical in vitro growth of hematopoietic precursor cells from MDS patients [2-4]. Further on, some newer laboratory techniques, like flow cytometry and next-generation sequencing (NGS), allowed better insight into the distinct pathological events underlying MDS development. Over last decades, with increased lifespan, a number of peripheral blood cytopenias were found to precede clinical MDS, especially, in the patients $>65$ years old, i.e., ICUS (idiopathic cytopenia of undetermined significance); CHIP (Clonal hematopoiesis of indeterminate potential); CCUS (clonal cytopenia of undetermined significance). Such conditions are determined by the age-dependent accumulation of somatic mutations which may play a role in subsequent MDS development.

These disorders may be transformed to hematological malignancy at a frequency of ca. $0.5-1 \%$ per year [5-7]. The majority of associated gene mutations (e.g., DNMT3A, TET2, ASXL1, TP53, and JAK2) affect RNA splicing or epigenetic regulation. However, patients with long-term cytopenias and somatic mutations do not always exhibit morphological changes of blood cells corresponding to MDS criteria. Moreover, only distinct cytogenetic aberrations (del5q) and point mutations (SF3B1) are considered specific for MDS, whereas other mutations are relatively non-specific and could be 
revealed in other pathologies, e.g., in the myeloproliferative disorders [8] or aplastic anemia (Fig. 1). In the latter case, MDS frequency was demonstrated to be sufficiently higher than in general population which is determined by the mutational profile [9].

Occurrence of additional potentially pathogenic mutations is associated with increased MDS risk [10]. At diagnosis, two or more marker somatic mutations can be determined in most MDS patients [11]. In parallel to additional mutagenesis and clonal evolution of hematopoietic cells, the clinical manifestations undergo several stages, from a cytopenia of undetermined significance to MDS, and, in some cases, to leukemic transformation into acute myeloid leukemia (AML) [12]. Due to this complex pathogenesis effective target therapy is still not available for this group of diseases despite better awareness of MDS development mechanisms.

\section{Hematopoietic cell transplantation and current therapeutic options}

At the present time, allogeneic HSCT is the only curative treatment method for MDS. However, patients with MDS still remain the most complicated candidates for allo-HSCT, due to a number of additional unfavorable factors, including advanced age of the patients. MDS is more common in the patients over 65 years old, which determines a sufficient number of co-morbidities. In addition, preceding prolonged therapy is associated with significant number of blood transfusions with high frequency of clinical and laboratory signs of iron overload, as well as immunization due to these transfusions. In clinical practice, reduced-intensity conditioning regimens are often applied, taking into account somatic state of patients [14]. However, hematological remission is not achieved at the time of allo-HSCT in the majority of patients.

Along with gene mutations in stem cells, a special feature of MDS pathogenesis are certain defects of hematopoietic microenvironment, which alter functioning of hematopoietic niches [15]. These alterations contribute to higher incidence of graft failure, including primary graft failure and severe poor graft function after engraftment, as well as increased probability of early relapse. Long cytopenias after allo-HSCT is associated with higher risk of infectious complications, which are the main cause of posttransplant mortality in MDS patients. All issues described above determine higher post-transplant mortality in MDS compared to the other groups of HSCT recipients $[16,17]$. Moreover, a significant proportion of patients is lacking HLA-compatible related or unrelated donor, and efficiency of haploidentical HSCT in MDS is still not supported by large studies [18]. According to the current European Blood and Marrow Transplantation (EBMT) guidelines, allo-HSCT from haploidentical donor is a clinical option and could be considered only after thorough evaluation of potential risks and benefits associated with this procedure.

Nonetheless, allo-HSCT facilitates cure in $30-40 \%$ of MDS patients. Several studies are ongoing aiming to improve alloHSCT outcomes with posttransplant relapse preventive strategies $[19,20]$.

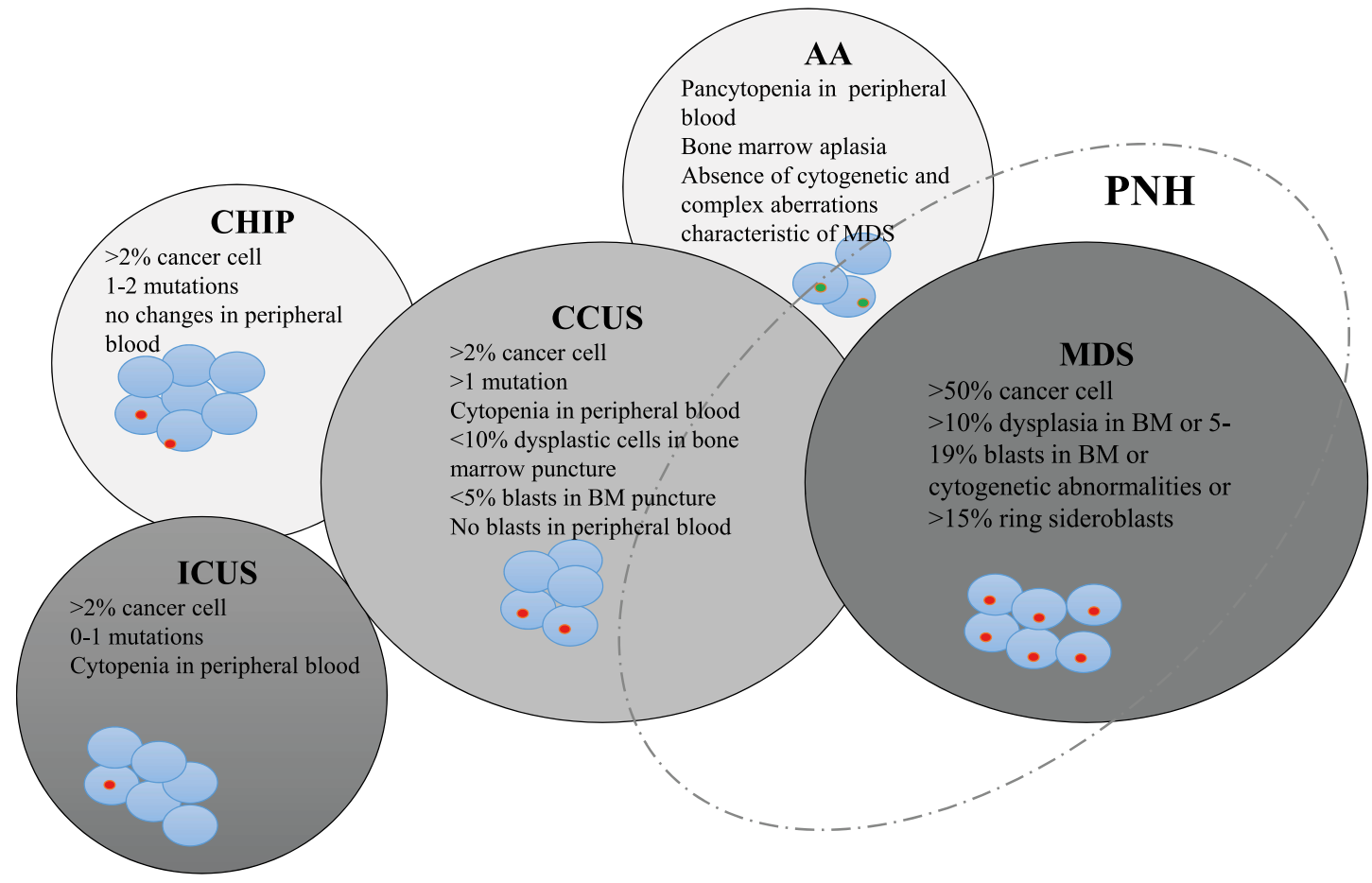

Figure 1. Interactions and characteristic features of clonal hematopoiesis of indetermined potential (CHIP), idiopathic cytopenia of undetermined significance (ICUS), clonal cytopenia of undetermined significance (CCUS), aplastic anemia (AA), and myelodysplastic syndrome (MDS). Adapted from Young N., 2002 [13] 
Due to clinical heterogeneity of MDS and risks associated with HSCT procedure, the strategy of treatment is largely personalized, dependent on the prognostic group, according to national and international recommendations [21,22].

In low- and very low-risk patients with predominant clinical signs of anemia, the main therapeutic goal is to reduce transfusion dependence and to prevent organ damage caused by iron overload. Erythropoiesis-stimulating agents (ESA) could be administered, which, however, are clinically effective in about $1 / 3$ of the patients, according to the multicenter studies [23]. The responders are predominantly those with initially low erythropoietin levels $(<200 \mathrm{ng} / \mathrm{ml})$ and the median duration of clinical response is about 1 year. Some studies suggest the possibility of decreased transfusion requirements with chelator therapy [24]. However, a randomized study did not show any improvement of erythropoietic response compared to ESA monotherapy [25].

In low-risk MDS cases with 5q- chromosomal aberration, immunomodulating therapy may result into cytogenetic remission in about $50 \%$ of the patients, with $2 / 3$ of cases becoming transfusion-independent $[26,27]$. In other low-risk MDS variants, there are only several single-center studies, where transfusion independence was achieved after short courses of hypomethylating agents (HMA) [28], and immunosuppressive treatment (IST), including cyclosporine $\mathrm{A}$ and anti-thymocyte globulin [29]. The median duration of clinical response using these therapies was, respectively, 16 and 18 months. Only small proportion of MDS patients has long-term remissions, either with HMA or IST protocols. However Kokhno A. et al. have shown that IST proved to be more effective in the patients with hypocellular bone marrow, or non-uniform cellularity with hypoplastic/aplastic areas, in absence of poor and very poor karyotype abnormalities according to IPSS-R scale, or without 7q-, i(17q) aberration [30].

In high-risk MDS, low-dose cytosine arabinoside (LDAC) treatment was a long-standing approach to therapy in myeloid dysplasia since mid-80's [31]. Median survival time in clinical studies was ca. 8 months for these cohorts, with maximal lifespan of 2-3 years and frequency of clinical responses of 15 to $30 \%$. However, some studies did not show any differences in survival rates between LDAC protocol and best supporting therapy [32-34]. At the present time, HMA became another standard of therapy in high-risk MDS. In registration randomized studies, decitabine and 5-azacitidine were associated with prolonged median survival by 2.7 and 10 months, respectively, compared with best available treatment $[35,36]$. Nevertheless, large clinical studies, e.g., Surveillance, Epidemiology, and End Result-Medicare database embracing 532 MDS high-risk patients, have shown somewhat higher results, i.e., median overall survival (OS) of, respectively, 11 and 12 months for decitabine and 5-azacitidine [37]. Despite MDS complete remissions are rare in HMA-treated MDS patients, these drugs enable temporary control of the disease with good quality of life and low hematological toxicity. Moreover, in the context of allo-HSCT, HMA may be effective in the pre-transplant period, by improving the patient's state during search and activation of potential donors without increase of hematological toxicity [38].

There also are some studies on improvement of platelet counts with supplementary treatment with Eltrombopag, however, without evidence of higher response rate $[39,40]$.

Despite improvements with HMA introduction, recent studies in fundamental biology and pathogenesis of MDS revealed potential opportunities for studying novel treatments able to modify specific signaling and metabolic pathways, as well as hematopoietic and immune microenvironment.

\section{Transforming growth factor-beta (TGF $\beta$ ) antagonists}

TGF $\beta$ antagonists, e.g. luspatercept, proved to be potentially effective in low-risk MDS with transfusion dependence, given the key role of TGF $\beta$ ligands in hematopoiesis. This drug represents a recombinant protein able to bind the TGF $\beta$ superfamily ligands, thus blocking SMAD2 and SMAD3 signaling pathways, regulating differentiation and maturation of erythroid precursors [41, 42]. These pathways play an
A

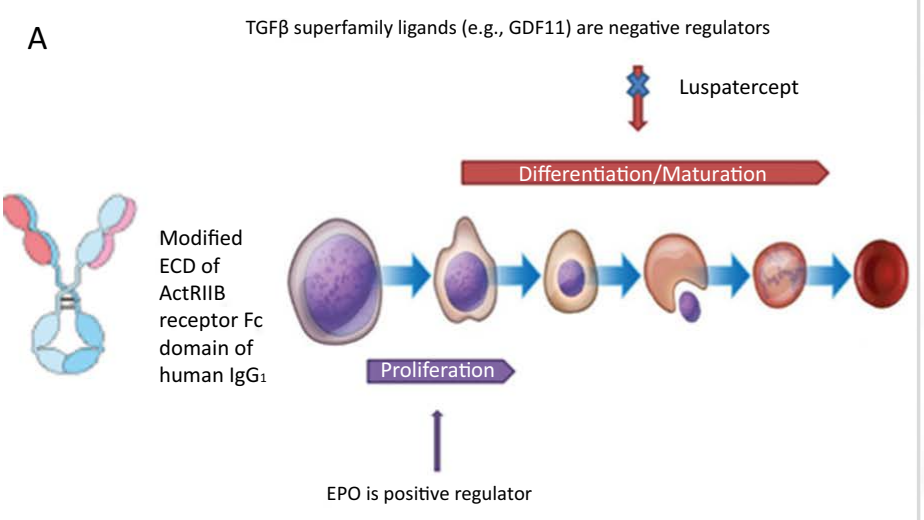

B

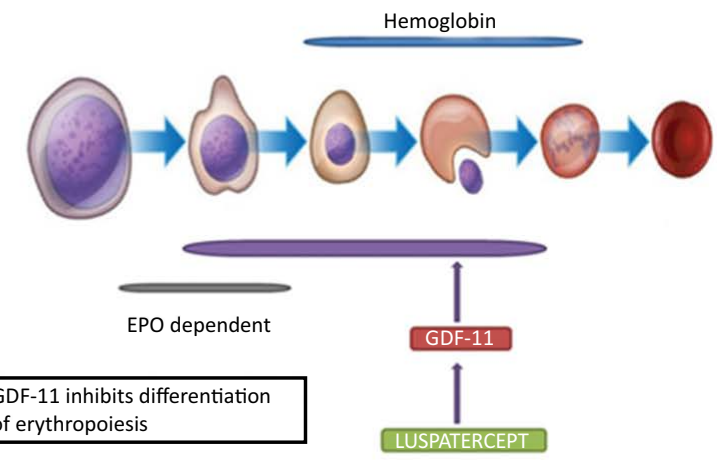

of erythropoiesis 
important role in MDS pathogenesis by inhibition of SMAD7 and SKI expression $[43,44]$. Luspatercept binds TGF $\beta$ ligands, that abrogating negative erythropoiesis regulation, accelerating events during late RBC maturation, unlike erythropoietin which regulates early stages of erythropoiesis [45], as shown in Fig. 2.

A general reduction in transfusion dependence was demonstrated in phase II clinical trial PACE-MDS with $29 \%$ of cases being with high transfusion requirements. Independence of blood transfusions was achieved in $36 \%$ of the cases. In particular, clinical responses were more often observed among patients with marrow ring sideroblasts and SF3B1 mutation [46].

In the phase 3 MEDALIST study, 37.9\% of low-risk MDS patients became transfusion-independent in the treatment with luspatercept compared to $13.2 \%$ in the placebo group. According to the results of longitudinal observation (MEDALIST study), independence on red blood cell (RBC) transfusions maintained for at least 8 weeks at any period of treatment, and it was more frequent among patients treated with luspatercept (47.7\%) than in placebo group (15.8\%). Approximately 1 year after initiation of luspatercept, $31.4 \%$ did not require RBC transfusions, against $0 \%$ in placebo group. Among luspatercept-treated patients, the overall transfusion-free period and clinical improvement was observed, independent on previous transfusion burden. Transfusion independence persisted in 12 cases $(7.8 \%)$ out of 153 patients who received luspatercept after 48 weeks of follow up. Some adverse effects associated with luspatercept administration rarely caused early discontinuation of therapy, and their occurrence decreased over time. Frequency of progression to AML (5\%) was similar for luspatercept-treated patients and placebo group [47].
Another randomized phase III study COMMANDS is ongoing, where a comparison is made between luspatercept and erythropoietin $\alpha$, the current standard of therapy [48]. The results of this study may influence the subsequent treatment standards in low-risk MDS patients. Similarly, some preclinical and clinical studies of kinase inhibitors involved into the TGF $\beta$ signal pathway are currently underway.

Galunisertib, an inhibitor of ALK5 kinase related to the signal transduction for TGF $\beta$ receptor activation, was studied in phase 2 clinical trials in low- and intermediate risk MDS, according to the IWG 2000 criteria. In $43.9 \%$ of patients, erythroid response was observed, hematological improvement was registered in $24.4 \%$ of cases, along with reduction of weakness in $44 \%$ of the patients. The results may justify its application in transfusion-dependent MDS patients who are non-responding to ESA [49]. Thus, a new class of TGF $\beta$-directed drugs can be registered in the near future. The ongoing studies will show if these drugs are applicable only in MDS with ring sideroblasts, or they could be extended to other subgroups of low-risk MDS patients.

Another agent for low-risk MDS in late clinical trials is Roxadustat. It is a protein factor regulating HIF-1a (hypoxia-inducible factor- $\alpha$ ) [50]. The drug influences erythropoietin production and iron uptake from macrophages, enhances iron metabolism, stabilizes blood HIF levels and prevents its degradation, thus promoting erythropoiesis [51]. Interim results of a multicenter study involved 24 patients with low-risk MDS and demonstrated a decrease of transfusion dependence by 50\% [52]. Roxadustat inhibits HIF- $\alpha$ decay followed by its dimerization with HIF- $\beta$ and nuclear translocation to cellular nucleus where the response to hypoxia is mediated at the transcriptional level (Fig. 3).

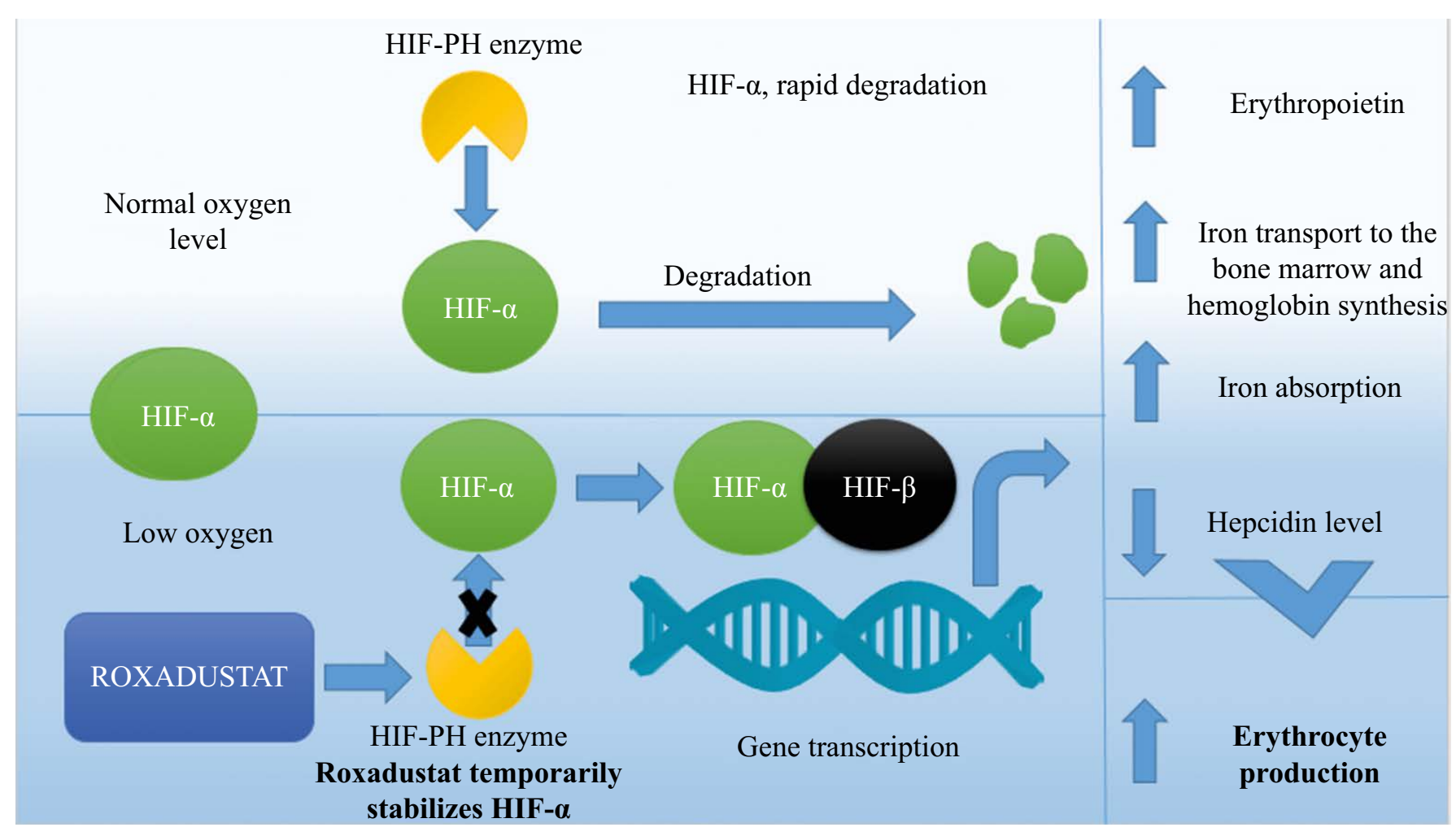

Figure 3. Main effects of roxadustat upon different organs and cells 


\section{Immune checkpoint inhibitors}

The inhibitors of immune checkpoints (ICP) are highly effective in a treatment of some solid tumors. Their versatile effects are based on reactivation of exhausted immune cells via blocking appropriate inhibitory signal, leading to a recovery of antitumor immunity. Nevertheless, the characteristics and expression of different ligands of ICP strongly depends on the type of malignancy. Pronounced clinical response to ICP is prominent in tumors with high neo-antigen contents, or amplification of genes encoding ICP ligands. Highest sensitivity to ICP treatment was demonstrated for Hodgkin's lymphoma, melanoma, cancers of urinary tract, lung cancer, head and neck malignancies, solid cancers with microsatellite instability [53]. There are usually only a small number of somatic mutations in MDS patients despite variable mutation profile [11], however hematopoietic cells in MDS exhibit high expression of the ICP ligands which may be increased during HMA therapy $[54,55]$.

Nonetheless, the ICP monotherapy was not associated with significant response in clinical trials [56]. The failure of nivolumab or ipilimumab monotherapy may be due to simultaneous expression of several inhibitors of immune response as confirmed by experimental data, including our own results [57]. Garcia-Manero G. et al. have shown the overall response rate $(69 \%)$ to 5 -azacitidine+nivolumab treatment in MDS, including complete remission in 2 patients. Higher response rate in this combined treatment schedule correlates with induction of neoantigen expression in tumor cells under HMA, thus enhancing the T cell immune response.

Failure of ICP therapy in MDS could be also determined by immunosuppressive effects in the hematopoietic niches. As possible mechanisms, one may consider high indoleamine-pyrrole 2,3-dioxygenase (IDO) expression in cellular microenvironment, $\mathrm{T}$ cell differentiation towards regulatory $\mathrm{T}$ cells, low interferon- $\alpha$ expression by $\mathrm{T}$ cells, induction of
T cell apoptosis due to activation of CD33-S100A9 signaling, increased levels of myeloid suppressor cells [58-68]. In future, ICP-based treatment seems to enter the standards of MDS therapy, however, not as monotherapy, but as combined therapeutic schedules, e.g., with PD-1, CTLA4 and TIM3 inhibitors [69]. Clinical trials with anti-TIM3 monoclonal antibodies are underway now. A multicenter study has shown that combined treatment with MBG453B, an anti-TIM3 antibody, and decitabine resulted into hematological or molecular remission in $50 \%$ of high-risk MDS patients [70].

Macrophage ICPs represent a fundamentally new class of such regulatory molecules. CD47, being expressed on macrophages, is a key molecule able to inhibit their response, and its interaction with SIRPa ligand protein causes suppression of phagocytic function. This effect is called a blocking "don't eat me" signal of CD47-SIRPa. This signal pathway is active during interactions between hematopoietic cells and macrophages, also serving as a tolerance mechanism in hematopoietic malignancies [71]. Magrolimab, or 5F9 antibody, is a humanized monoclonal antibody (MAb) which blocks CD47 and activates SIRPa pathway, promotes phagocytosis of tumor cells. Combined application of this drug with 5 -azacitidine in preclinical model of acute myeloid leukemia (AML) has shown high survival rates in laboratory animals [72]. During the Phase 1 clinical trial, 5-azacitidine and Magrolimab was administered to 35 high-risk MDS patients. The response was evaluated in 24 patients, with hematological response in $92 \%$ and complete remission in $50 \%$ of the cases. Further observations are required to assess duration of the responses [73].

Distinct effects of the CD47-blocking antibodies are considered, as follows: (a) under normal conditions, both healthy and malignant cells are avoiding phagocytosis by CD47 expression. CD47 is overexpressed by cancer cells for protection from eat me/prophagocyte signals. (b) After the
A

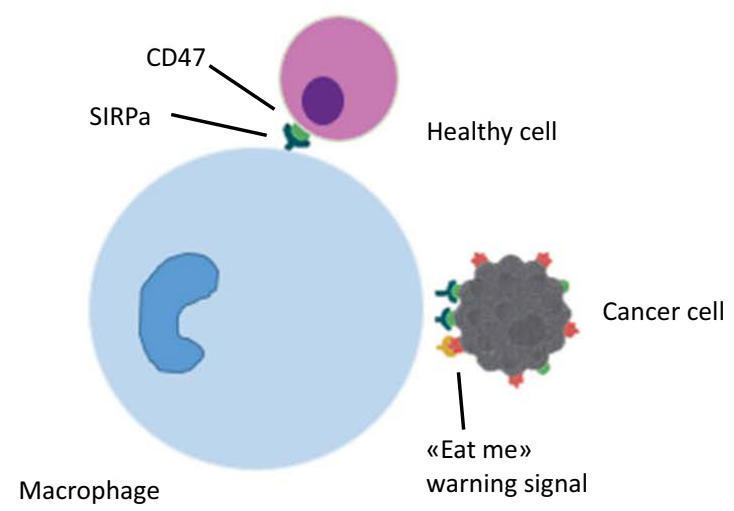

B

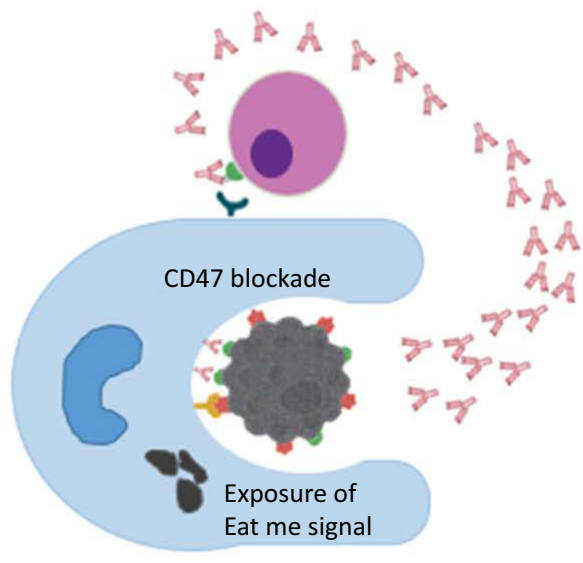


Mab-induced CD47 blockage, the malignant cells are phagocytized, thus causing exposure of the eat me signal. By contrast, normal cells remain intact due to absent expression of prophagocytic signals.

\section{Inhibitors of bcl2, hedgehog, IDH and other molecular targets}

Over last years, a significant role of bcl 2 in AML progression and drug resistance was elucidated. Venetoclax, a specific bcl2 inhibitor, was shown to increase the rates of complete remission in combination with LDAC or HMA $[74,75]$. However, the results observed in AML cannot be blindly extended to MDS. BCL2 inhibition in an MDS models leads to suppression of apoptosis in hematopoietic cells and transition to the resting phase of a cell cycle. As a result a reduced DNA damage of erythropoietic precursors was observed. However, some doubts exist since apoptosis blockage may promote faster transition to AML [76].

Overall response to venetoclax was $21 \%$ in a group of chemotherapy-refractory AML and MDS patients [77]. Clinical studies are ongoing with early venetoclax and HMA administration in MDS. So far only the results of non-randomized studies are published demonstrating promising overall and complete remission rates (59\% and $14 \%$, respectively) even in HMA-exposed patients [78].

Glasdegib, another inhibitor of signaling pathways, was registered in 2019 for therapy of AML and high-risk MDS in combination with chemotherapy. The drug inhibits Hedgehog $(\mathrm{Hh})$ pathway previously described as an embryogenesis regulator, since Hh proteins are involved in cell and tissue differentiation. Like other intracellular signaling systems, the Hh pathway plays an important role in cell cycle regulation of malignant cells and is involved into the mechanisms of chemotherapy resistance [79].

In a Phase I study, $31 \%$ of AML and high-risk MDS patients have achieved complete remission during the glasdegib therapy combined with LDAC and decitabine [80]. Complete remission was achieved in $46 \%$ of the patients with similar disorders in another study using glasdegib combined with systemic $7+3$ chemotherapy [81]. In a randomized study comparing glasdegib plus LDAC against LDAC a 3-month increase in OS was demonstrated, along with long-term stabilization of the disease in some patients. The rates of response to glasdegib monotherapy in refractory MDS comprise only $6 \%$ [82]. Chaudhry et al. noted that therapeutic activity of glasdegib requires expression of GLI3 suppressor gene which may be hypermethylated in MDS and AML. Determination of GLI3 expression may serve as predictor of response to glasdegib treatment [83]. Despite relatively low efficiency, glasdegib is well tolerated, thus allowing to suggest it as a component of combined therapy in MDS.

About $5 \%$ of MDS cases are associated with IDH1 and IDH2 gene mutations. The mutated IDH variants are associated with excessive production of R2-hydroxyglutarate which causes functional insufficiency of TET2 gene [84, 85]. Presently, two IDH inhibitors for oral administration are under clinical trials, enasidenib, and ivosidenib (respectively for
IDH2 and IDH1 inhibition). The Phase II study in AML and high-risk MDS patients, enasidenib therapy was associated with response in $53 \%$ of the patients including complete remission in 7\% [86]. There are no preliminary results on ivosidenib in MDS at the present moment. However, in elderly AML ivosidenib induced complete remission, including one with partial hematologic recovery, in $42.4 \%$ of patients and median duration of remission was not reached with 2 -year follow up [87].

Rigosertib is another clinically tested inhibitor of signal pathways which is able to suppress several kinases, e.g., Akt, PI3K. A clinical study in MDS patients has demonstrated reduction of blastosis [88]. However, Phase III study in HMA-resistant patients did not show any differences in survival between Rigosertib treatment and best available therapy [89]. At present, Rigosertib is tested in combination with 5-azacitidine [90].

A small group of MDS patients exhibits FLT3 mutation [11]. These patients are prone to rapid transformation to AML, thus precluding data accumulation on clinical efficiency of FLT3 inhibitors in this MDS variant. Nevertheless, the MDS experience shows that addition of Midostaurin to chemotherapy is associated with $8 \%$ increase in relapse-free survival [91]. The response rate in combined therapy with 5-azacitidine was 26\% [92]. Meanwhile, the second-generation FLT3 inhibitors (Gilteritinib and Quizartinib) demonstrate more optimistic results [93, 94], thus creating the basis for addition of these agents to standard therapy in MDS patients with FLT3 mutations.

Summarizing the overview of developing targeted therapies, it is important to mention that few of them induce high complete remission rate and these complete remissions are not durable in the high proportion of the patients. When keeping in mind the complex pathogenesis of this disease, it is clear that complex approaches to therapy are required. The successful examples of other hematological diseases give us hope for long-term improvement of survival in MDS (Fig. 5).

\section{Allogeneic HSCT as a platform for immune therapy in MDS patients}

Along with development of novel therapeutic molecules, some feasible options of cellular therapy are under investigation in MDS [95]. At the moment, allo-HSCT is the only cellular therapy in MDS which is widely used in clinical practice. However, allo-HSCT is a high-risk procedure with potentially severe complications that may cause sufficiently decreased quality of life and shorter survival of the patients. This issue is especially important due to advanced age of most MDS patients, thus increasing risk for dismal outcome.

To evaluate the impact of allo-HSCT on survival in MDS we compared the survival of two contemporary cohorts of patients treated at RM Gorbacheva Research Institute. The first cohort agreed to allograft procedure while the second refused to undergo allo-HSCT and was treated with available therapies. Although the groups were not well matched, however represent the real life clinical practice at large HSCT 


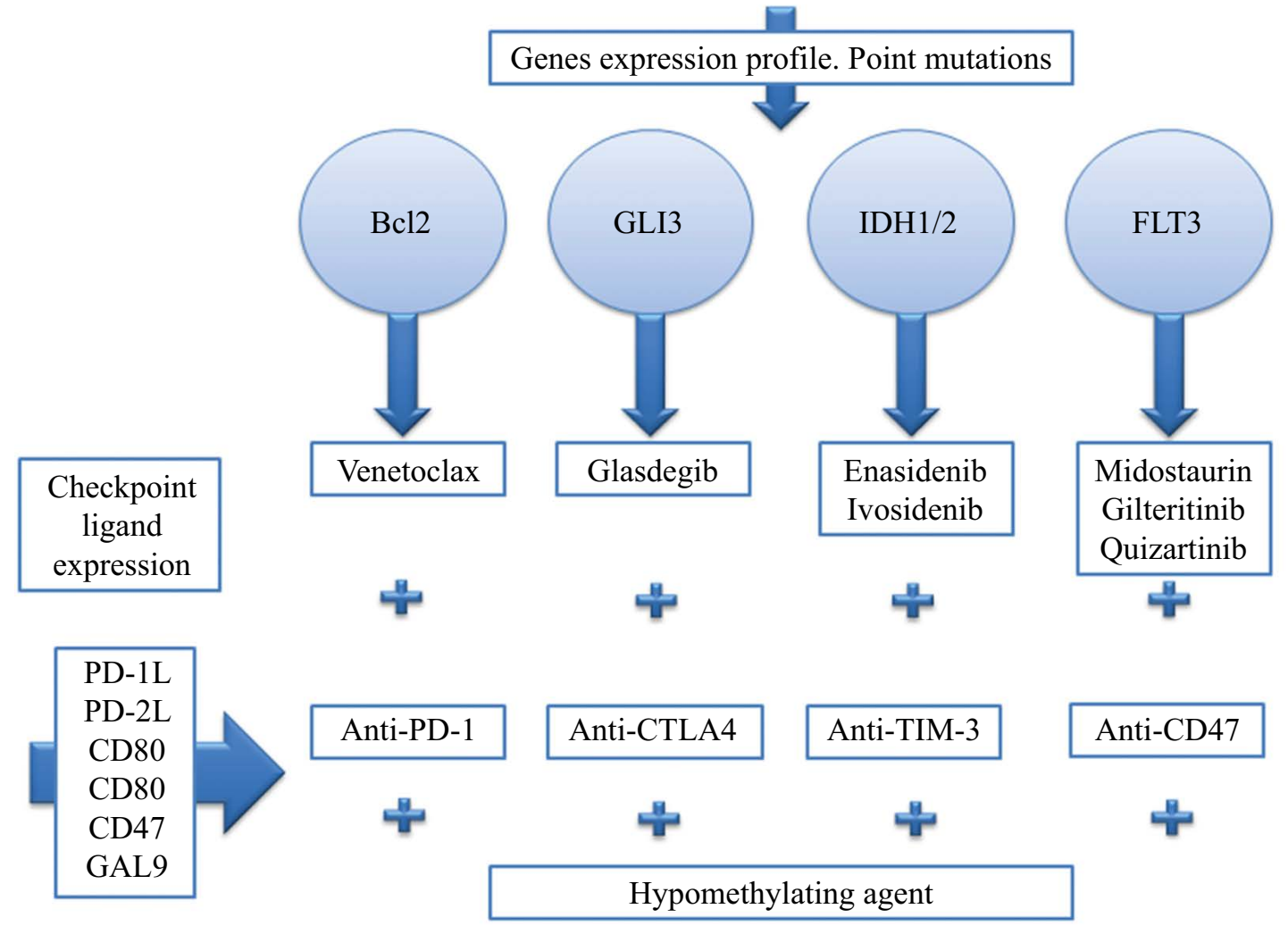

Figure 5. Potential drug combinations in personalized therapy of high-risk MDS

A 2-year overall survival rate

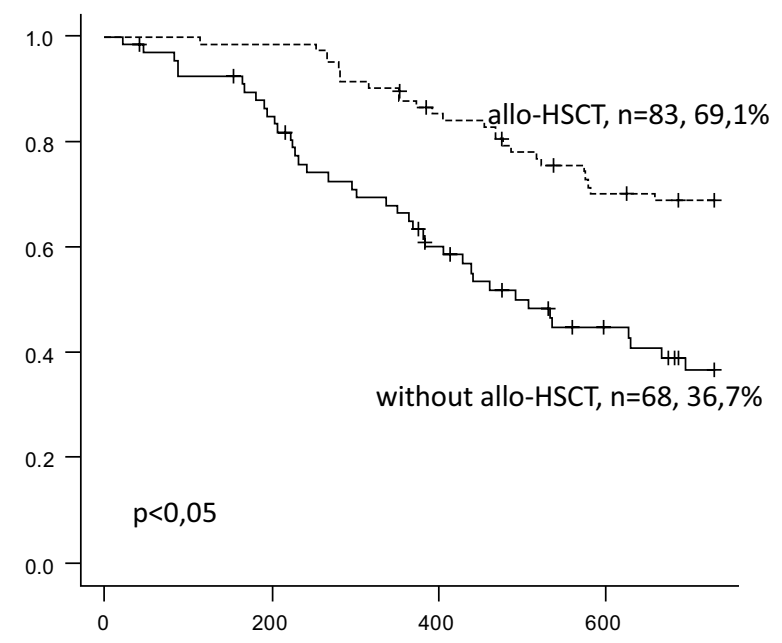

Time, days
B 2-year overall survival rate

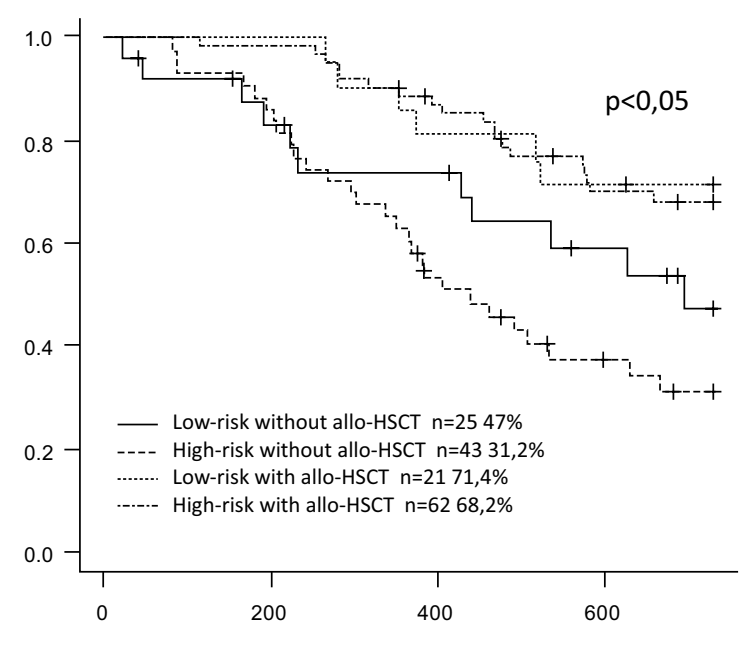

Time, days

Figure 6. Two-year overall survival of MDS patients depending on allo-HSCT performed (A). The two-year overall survival of MDS patients depending on allo-HSCT performed and IPSS risk group (B)

center. The comparison of these two groups revealed that two-year OS in MDS patients without allo-HSCT was 36.7\% $(\mathrm{n}=68)$, while it was $69.1 \%(\mathrm{n}=83)$ among the patients after HSCT ( $<<0.05$ ) (Fig. 6A). In allo-HSCT group, the 2 -year OS was comparable in IPPS- $\mathrm{R}$ intermediate- 2 versus high-risk groups $(\mathrm{n}=62)$, and intermediate- 1 versus low-risk groups $(\mathrm{n}=21,68.2 \%$ vs $71.4 \%$, respectively). Two-year overall survival was lower in similar patient groups without allo-HSCT:
31.2\% $(\mathrm{n}=43)$ and $47 \%(\mathrm{n}=25, \mathrm{p}<0.05)$, respectively (Fig. $6 \mathrm{~B})$. The survival rates following HSCT depended on the following items: disease status, graft composition, infectious complications, acute GvHD grade I-II [16]. Interestingly, the evaluation of all existing MDS prognostic scales in our MDS allo-HSCT group did not exert any significant effects on survival after allo-HSCT. This observation highlights a necessity to validate developing scales in the center- or country- 
stratified manner. Hence, it is clear that the risk-adapted strategies in MDS patients are of extreme importance.

So far, it is unclear how the role of allo-HSCT in MDS will change. It can follow the track of chronic lymphocytic leukemia [96] and Hodgkin's lymphoma [97] where effective bridging before allo-HSCT brought the results of allo-HSCT in refractory disease close to the results of primary treatment in these malignancies. In this situation, allo-HSCT will be more broadly used in MDS. On the other hand, combination therapies can bring durable remissions to this difficult population of patients. In this case allo-HSCT will be brought from first line to second or subsequent lines of therapy like it happened with chronic myeloid leukemia [98]. Given the preliminary favorable results of allo-HSCT in MDS after therapy with ICPs [99], it is likely that at least the first scenario with effective bridging therapies will be implemented in the near future.

\section{Conclusion}

With respect to recent findings and genetic studies made by means of NGS techniques, some radical changes are expected in MDS therapies. The drug selection will be based on evaluation of mutational profile, expression of checkpoint molecules and methylation profile. The results of these studies will determine a combination of target agents, ICP inhibitors and hypomethylating agents. It is also clear that allo-HSCT will remain in MDS clinical practice, however its place in a sequence of therapies will be rapidly changing.

\section{Acknowledgements}

The work was supported by Russian Science Foundation grant 17-75-20145-П.

\section{Conflict of interest}

The authors declare no conflicts of interest.

\section{References}

1. Sperling AS, Gibson CJ, Ebert BL. The genetics of myelodysplastic syndrome: from clonal haematopoiesis to secondary leukaemia. Nat Rev Cancer. 2017;17(1):5-19. doi:10.1038/nrc.2016.112.

2. Tiranova SA, Alekseev NA, Petrova EM, et al. On the question of the existence of hematopoietic dysplasia (preleukemia) in children. Terapevticheskii arkhiv. 1982;54(8):1-16 (In Russian).

3. Afanasyev BV, Tiranova SA, Kulibaba TG, et al. Cloning of human hematopoietic cells in agar drop-liquid medium system. Terapevticheskii arkhiv. 1983;54(8):114-22 (In Russian).

4. Kleihauer E. The preleukemic syndromes (hematopoietic dysplasia) in childhood. Eur J Pediatr. 1980;133(1):5-10.

5. Busque L, Patel JP, Figueroa ME, Vasanthakumar A, Provost S, Hamilou Z, et al. Recurrent somatic TET2 mutations in normal elderly individuals with clonal hematopoiesis. Nat Genet. 2012;44(11):1179-1181. doi:10.1038/ng.2413.
6. Genovese G, Kähler AK, Handsaker RE, Lindberg J, Rose SA, Bakhoum SF, et al. Clonal hematopoiesis and blood-cancer risk inferred from blood DNA sequence. N Engl J Med. 2014;371(26):2477-2487. doi:10.1056/NEJMoa1409405.

7. Jaiswal S, Fontanillas P, Flannick J, Manning A, Grauman PV, Mar BG, et al. Age-related clonal hematopoiesis associated with adverse outcomes. N Engl J Med. 2014;371(26):24882498. doi:10.1056/NEJMoa1408617.

8. Malcovati L, Cazzola M. The shadowlands of MDS: idiopathic cytopenias of undetermined significance (ICUS) and clonal hematopoiesis of indeterminate potential (CHIP). Hematology Am Soc Hematol Educ Program. 2015;2015:299307. doi:10.1182/asheducation-2015.1.299.

9. Afanasyev B.V., Zubarovskaya L. Pediatric myelodysplastic syndrome. Russian Journal of Pediatric Hematology and Oncology. 2018;5(3):23-35. (In Russian). doi: 10.17650/23111267-2018-5-3-23-35.

10. Malcovati L, Gallì A, Travaglino E, Ambaglio I, Rizzo E, Molteni E, et al. Clinical significance of somatic mutation in unexplained blood cytopenia. Blood. 2017;129(25):33713378. doi:10.1182/blood-2017-01-763425.

11. Papaemmanuil E, Gerstung M, Malcovati L, Tauro S, Gundem G, Van Loo P, et al. Clinical and biological implications of driver mutations in myelodysplastic syndromes. Blood. 2013;122(22):3616-3699. 吕:10.1182/ blood-2013-08-518886.

12. Duarte RF, Labopin M, Bader P, Basak GW, Bonini C, Chabannon $\mathrm{C}$, et al. Indications for haematopoietic stem cell transplantation for haematological diseases, solid tumours and immune disorders: current practice in Europe, 2019. Bone Marrow Transplant. 2019;54(10):1525-1552. doi:10.1038/s41409-019-0516-2.

13. Young NS. Acquired aplastic anemia. Ann Intern Med. 2002;136(7):534-546. doi:10.7326/0003-4819-136-7200204020-00011.

14. Kröger N, Iacobelli S, Franke GN, Platzbecker U, Uddin $\mathrm{R}$, Hübel K, et al. Dose-reduced versus standard conditioning followed by allogeneic stem-cell transplantation for patients with myelodysplastic syndrome: A prospective randomized Phase III Study of the EBMT (RICMAC Trial). J Clin Oncol. 2017;35(19):2157-2164. doi:10.1200/JCO.2016.70.7349.

15. Li AJ, Calvi LM. The microenvironment in myelodysplastic syndromes: Niche-mediated disease initiation and progression. Exp Hematol. 2017;55:3-18. doi:10.1016/j.exphem.2017.08.003.

16. Morozova EV, Barabanshikova MV, Tcvetkov NY, Melsitova KV, Rudnitskaya JV, Darskaya EI, et al. Application of standard and novel prognostic systems in patients with myelodysplastic syndrome undergoing allogeneic hematopoietic stem cell transplantation. Cell Ther Transplant 2019; 8(1): 36-45. doi: 10.18620/ctt-1866-8836-2019-8-1-36-45.

17. Kröger N, Zabelina T, de Wreede L, Berger J, Alchalby H, van Biezen A, et al. Allogeneic stem cell transplantation for older advanced MDS patients: improved survival with young unrelated donor in comparison with HLA-identical siblings. Leukemia. 2013;27(3):604-609. doi:10.1038/leu.2012.210. 
18. Wang Y, Wang HX, Lai YR, Sun ZM, Wu DP, Jiang M, et al. Haploidentical transplant for myelodysplastic syndrome: registry-based comparison with identical sibling transplant. Leukemia. 2016;30(10):2055-2063. doi:10.1038/leu.2016.110.

19. El-Cheikh J, Massoud R, Fares E, Kreidieh N, Mahfouz $\mathrm{R}$, Charafeddine $\mathrm{M}$, et al. Low-dose 5-azacytidine as preventive therapy for relapse of AML and MDS following allogeneic HCT. Bone Marrow Transplant. 2017;52(6):918-921. doi:10.1038/bmt.2017.31.

20. Ovechkina VN, Bondarenko SN, Morozova EV, et al. The role of hypomethylating agents prior to allogeneic hematopoietic stem cells transplantation in acute myeloid leukemia and myelodysplastic syndrome. Clinical Oncohematology. 2017;10(3):351-357 (In Russian). doi: 10.21320/2500-21392017-10-3-351-7.

21. Savchenko VG, Parovichnikova EN, Kokhno AV, et al. National clinical guidelines for the diagnosis and treatment of myelodysplastic syndromes adults. Hematology and Transfusiology (Gematologiya i transfusiologiya). 2016; 61 (1-32). doi: 10.18821/0234-5730-2016-61-1 (In Russian).

22. Greenberg PL, Tuechler H, Schanz J, Sanz G, Garcia-Manero G, Solé F, et al. Revised international prognostic scoring system for myelodysplastic syndromes. Blood. 2012;120(12):2454-2465. doi:10.1182/blood-2012-03-420489.

23. Fenaux P, Santini V, Spiriti MAA, Giagounidis A, Schlag $\mathrm{R}$, Radinoff $\mathrm{A}$, et al. A phase 3 randomized, placebo-controlled study assessing the efficacy and safety of epoetin- $\alpha$ in anemic patients with low-risk MDS. Leukemia. 2018;32(12):2648-2658. doi:10.1038/s41375-018-0118-9.

24. Latagliata R, Montagna C, Porrini R, Di Veroli A, Leonetti SC, Niscola $\mathrm{P}$, et al. Chelation efficacy and erythroid response during deferasirox treatment in patients with myeloproliferative neoplasms in fibrotic phase. Eur J Haematol. 2016;96(6):643-649. doi:10.1111/ejh.12674.

25. Gattermann N, Coll R, Jacobasch L, Allameddine A, Azmon A, DeBonnett L, et al. Effect of deferasirox + erythropoietin vs erythropoietin on erythroid response in Low/ Int-1-risk MDS patients: Results of the phase II KALLISTO trial [published online ahead of print, 2018 May 19]. Eur J Haematol. 2018;10.1111/ejh.13096. doi:10.1111/ejh.13096.

26. Garcia-Manero G, Almeida A, Fenaux P, Gattermann N, Giagounidis A, Goldberg SL, et al. Clinical benefit-risk profile of lenalidomide in patients with lower-risk myelodysplastic syndromes without $\operatorname{del}(5 \mathrm{q})$ : Results of a Phase III Trial. Clin Lymphoma Myeloma Leuk. 2019;19(4):213-219. e4. doi:10.1016/j.clml.2018.12.012.

27. Lee JH, List A, Sallman DA. Molecular pathogenesis of myelodysplastic syndromes with deletion 5q. Eur J Haematol. 2019;102(3):203-209. doi:10.1111/ejh.13207.

28. Jabbour E, Short NJ, Montalban-Bravo G, Huang X, Bueso-Ramos C, Qiao W, et al. Randomized phase 2 study of low-dose decitabine vs low-dose azacitidine in lower-risk MDS and MDS/MPN. Blood. 2017;130(13):1514-1522. doi:10.1182/blood-2017-06-788497.

29. Passweg JR, Giagounidis AA, Simcock M, Aul C, Dobbelstein C, Stadler M, et al. Immunosuppressive therapy for patients with myelodysplastic syndrome: a prospective randomized multicenter phase III trial comparing antithymocyte globulin plus cyclosporine with best supportive care-SAKK 33/99. J Clin Oncol. 2011;29(3):303-309. doi:10.1200/ JCO.2010.31.2686.

30. Kokhno AV, Parovichnikova EN, Mikhailova EA, et al. Efficiency of cyclosporin A therapy in patients with myelodysplastic syndrome. Terapevticheskii Arkhiv. 2010; 82(8): 48-53 (In Russian).

31. Patterson D, Kravtsova VM, Petrova EM, et al. Therapy of patients with myeloid leukemia with low doses of cytosine arabinoside. Terapevticheskii Arkhiv. 1987; 12: 81-86 (In Russian).

32. Gerhartz HH, Marcus R, Delmer A, Zwierzina H, de Witte T, Jacobs A, et al. Treatment of myelodysplastic syndromes (MDS) and high leukaemic risk with low-dose cytosine arabinoside (LD-AraC) plus granulocyte-macrophage colony-stimulating factor (rh GM-CSF). The EORTC Leukaemia Group. Infection, 1992; 20 (Suppl 2):S116-S123. doi:10.1007/BF01705030.

33. Zwierzina H, Suciu S, Loeffler-Ragg J, Neuwirtova R, Fenaux P, Beksac M, et al. Low-dose cytosine arabinoside (LD-AraC) vs LD-AraC plus granulocyte/macrophage colony stimulating factor vs LD-AraC plus Interleukin-3 for myelodysplastic syndrome patients with a high risk of developing acute leukemia: final results of a randomized phase III study (06903) of the EORTC Leukemia Cooperative Group. Leukemia. 2005;19(11):1929-1933. doi:10.1038/ sj.leu. 2403934 .

34. Kokhno AV, Parovichnikova EN, Mikhailova EA, et al. Myelodysplastic syndromes and aplastic anemia. In the manual "Programmed treatment of diseases of the blood system: Collection of diagnostic algorithms and treatment protocols for diseases of the blood system" (ed. by VG Savchenko). State Research Center of the Russian Healthcare Ministry; Moscow: Practice (2012): 83-150 (In Russian).

35. Kantarjian HM, Thomas XG, Dmoszynska A, Wierzbowska A, Mazur G, Mayer J, et al. Multicenter, randomized, open-label, phase III trial of decitabine versus patient choice, with physician advice, of either supportive care or low-dose cytarabine for the treatment of older patients with newly diagnosed acute myeloid leukemia. J Clin Oncol. 2012;30(21):2670-2677. doi:10.1200/JCO.2011.38.9429.

36. Fenaux P, Mufti GJ, Hellstrom-Lindberg E, Santini V, Finelli C, Giagounidis A, et al. Efficacy of azacitidine compared with that of conventional care regimens in the treatment of higher-risk myelodysplastic syndromes: a randomised, open-label, phase III study. Lancet Oncol. 2009; 10(3):223-232. doi:10.1016/S1470-2045(09)70003-8.

37. Zeidan AM, Davidoff AJ, Long JB, Hu X, Wang R, Ma X, et al. Comparative clinical effectiveness of azacitidine versus decitabine in older patients with myelodysplastic syndromes. Br J Haematol. 2016;175(5):829-840. doi:10.1111/bjh.14305.

38. Field T, Perkins J, Huang Y, Kharfan-Dabaja MA, Alsina M, Ayala E, et al. 5-Azacitidine for myelodysplasia before allogeneic hematopoietic cell transplantation. Bone Marrow Transplant. 2010;45(2):255-260. doi:10.1038/bmt.2009.134. 
39. Mittelman M, Platzbecker U, Afanasyev B, et al. Eltrombopag for advanced myelodysplastic syndromes or acute myeloid leukaemia and severe thrombocytopenia (ASPIRE): a randomised, placebo-controlled, phase 2 trial. Lancet Haematol. 2018;5(1):e34-e43. doi:10.1016/S23523026(17)30228-4.

40. Dickinson M, Cherif H, Fenaux P, Mittelman M, Verma A, Portella MSO, et al. Azacitidine with or without eltrombopag for first-line treatment of intermediate- or high-risk MDS with thrombocytopenia. Blood. 2018; 132(25):26292638. doi:10.1182/blood-2018-06-855221.

41. Muench DE, Ferchen K, Velu CS, Pradhan K, Chetal K, Chen X, et al. SKI controls MDS-associated chronic TGF- $\beta$ signaling, aberrant splicing, and stem cell fitness. Blood. 2018;132(21):e24-e34. doi:10.1182/blood-2018-06-860890.

42. Zermati Y, Fichelson S, Valensi F, Freyssinier JM, Rouyer-Fessard P, Cramer E, et al. Transforming growth factor inhibits erythropoiesis by blocking proliferation and accelerating differentiation of erythroid progenitors. Exp Hematol. 2000;28(8):885-894. doi:10.1016/s0301-472x(00)00488-4

43. Zhou L, McMahon C, Bhagat T, Alencar C, Yu Y, Fazzari $\mathrm{M}$, et al. Reduced SMAD7 leads to overactivation of TGF-beta signaling in MDS that can be reversed by a specific inhibitor of TGF-beta receptor I kinase. Cancer Res. 2011;71(3):955-963. doi:10.1158/0008-5472.CAN-10-2933.

44. Bachegowda L, Gligich O, Mantzaris I, Schinke C, Wyville D, Carrillo T, et al. Signal transduction inhibitors in treatment of myelodysplastic syndromes. J Hematol Oncol. 2013;6:50. Published 2013 Jul 10. doi:10.1186/1756-8722-6-50.

45. Hanke T, Wong JF, Berger BT, Abdi I, Berger LM, Tesch $\mathrm{R}$, et al. A highly selective chemical probe for activin receptor-like kinases ALK4 and ALK5. ACS Chem Biol. 2020;15(4):862-870. doi:10.1021/acschembio.0c00076.

46. Platzbecker U, Germing U, Götze KS, Kiewe P, Mayer $\mathrm{K}$, Chromik J, et al. Luspatercept for the treatment of anaemia in patients with lower-risk myelodysplastic syndromes (PACE-MDS): a multicentre, open-label phase 2 dose-finding study with long-term extension study. Lancet Oncol. 2017;18(10):1338-1347. doi:10.1016/S1470-2045(17)30615-0.

47. Fenaux P, Platzbecker U, Mufti GJ, Garcia-Manero G, Buckstein R, Santini V, et al. Luspatercept in Patients with Lower-Risk Myelodysplastic Syndromes. N Engl J Med. 2020;382(2):140-151. doi:10.1056/NEJMoa1908892.

48. https://clinicaltrials.gov/ct2/show/NCT03682536, as of $12 / 2019$

49. Santini V, Valcárcel D, Platzbecker U, Komrokji RS, Cleverly AL, Lahn MM, et al. Phase II study of the ALK5 inhibitor galunisertib in very low-, low-, and intermediate-risk myelodysplastic syndromes. Clin Cancer Res. 2019; 25(23):69766985. doi:10.1158/1078-0432.CCR-19-1338.

50. https://clinicaltrials.gov/ct2/show/NCT03263091, as of $12 / 2019$

51. Chen N, Qian J, Chen J, Yu X, Mei C, Hao C, et al. Phase 2 studies of oral hypoxia-inducible factor prolyl hydroxylase inhibitor FG-4592 for treatment of anemia in China. Nephrol Dial Transplant. 2017;32(8):1373-1386. doi:10.1093/ndt/ gfx011.

52. Henry DH, Glaspy J, Harrup RA, Mittelman M, Zhou A, Bradley C, et al. Roxadustat (FG4592; ASP1517; AZD9941) in the treatment of anemia in patients with lower risk myelodysplastic syndrome (LR-MDS) and low red blood cell (RBC) transfusion burden (LTB). Blood 2019; 134 (Supplement_1): 843. doi: 10.1182/blood-2019-128714.

53. Allison JP. Checkpoints. Cell. 2015;162(6):1202-1205. doi:10.1016/j.cell.2015.08.047.

54. Chokr N, Patel R, Wattamwar K, Chokr S. The rising era of immune checkpoint inhibitors in myelodysplastic syndromes. Adv Hematol. 2018;2018:2458679. doi:10.1155/2018/2458679.

55. Yang H, Bueso-Ramos C, DiNardo C, Estecio MR, Davanlou $\mathrm{M}$, Geng $\mathrm{QR}$, et al. Expression of PD-L1, PD-L2, PD-1 and CTLA4 in myelodysplastic syndromes is enhanced by treatment with hypomethylating agents. Leukemia. 2014;28(6):1280-1288. doi:10.1038/leu.2013.355.

56. Garcia-Manero G, Daver NG, Montalban-Bravo G, Jabbour EJ, DiNardo CD, Kornblau SM, et al. A Phase II Study evaluating the combination of Nivolumab (Nivo) or Ipilimumab (Ipi) with Azacitidine in patients with previously treated or untreated myelodysplastic syndromes (MDS). Blood 2016; 128 (22): 344. doi: 10.1182/blood. V128.22.344.344.

57. Tcvetkov N, Gusak A, Morozova E, et al. Immune checkpoints bone marrow expression as the predictor of clinical outcome in myelodysplastic syndrome. Leuk Res Rep. 2020;14:100215. Published 2020 Jun 28. doi:10.1016/j. lrr.2020.100215.

58. Meisel R, Zibert A, Laryea M, Göbel U, Däubener W, Dilloo D. Human bone marrow stromal cells inhibit allogeneic T-cell responses by indoleamine 2,3-dioxygenase-mediated tryptophan degradation. Blood. 2004;103(12):4619-4621. doi:10.1182/blood-2003-11-3909.

59. Croitoru-Lamoury J, Lamoury FM, Caristo M, Suzuki $\mathrm{K}$, Walker $\mathrm{D}$, Takikawa $\mathrm{O}$, et al. Interferon- $\gamma$ regulates the proliferation and differentiation of mesenchymal stem cells via activation of indoleamine 2,3 dioxygenase (IDO). PLoS One. 2011;6(2):e14698. Published 2011 Feb 16. doi:10.1371/ journal.pone.0014698.

60. Corm S, Berthon C, Imbenotte M, Biggio V, Lhermitte $\mathrm{M}$, Dupont C, et al. Indoleamine 2,3-dioxygenase activity of acute myeloid leukemia cells can be measured from patients' sera by HPLC and is inducible by IFN-gamma. Leuk Res. 2009;33(3):490-494. doi:10.1016/j.leukres.2008.06.014.

61. Yuan Y, Lu X, Tao CL, Chen X, Shao HW, Huang SL. Forced expression of indoleamine-2,3-dioxygenase in human umbilical cord-derived mesenchymal stem cells abolishes their anti-apoptotic effect on leukemia cell lines in vitro. In Vitro Cell Dev Biol Anim. 2013;49(10):752-758. doi:10.1007/s11626-013-9667-4.

62. Curti A, Pandolfi S, Valzasina B, Aluigi M, Isidori A, Ferri E, et al. Modulation of tryptophan catabolism by human 
leukemic cells results in the conversion of CD25- into CD25+ T regulatory cells. Blood. 2007;109(7):2871-2877. doi:10.1182/blood-2006-07-036863.

63. Schnorfeil FM, Lichtenegger FS, Emmerig K, Schlueter M, Neitz JS, Draenert R, et al. T cells are functionally not impaired in AML: increased PD-1 expression is only seen at time of relapse and correlates with a shift towards the memory T cell compartment. J Hematol Oncol. 2015;8:93. Published 2015 Jul 30. doi:10.1186/s13045-015-0189-2.

64. Wendelbo Ø, Nesthus I, Sjo M, Paulsen K, Ernst P, Bruserud $\varnothing$. Functional characterization of T lymphocytes derived from patients with acute myelogenous leukemia and chemotherapy-induced leukopenia. Cancer Immunol Immunother. 2004;53(8):740-747. doi:10.1007/s00262-004-0505-0.

65. Lamble A, Kosaka Y, Huang F, Sasser AK, Adams H, Tognon CE, et al. Mass cytometry as a modality to identify candidates for immune checkpoint inhibitor therapy within acute myeloid leukemia. Blood 2016;128:2829. doi: https:// doi.org/10.1182/blood.V128.22.2829.2829.

66. Legat A, Speiser DE, Pircher H, Zehn D, Marraco SAF. Inhibitory receptor expression depends more dominantly on differentiation and activation than "exhaustion" of human CD8 T cells. Front Immunol. 2013;4:455. Published 2013 Dec 19. doi:10.3389/fimmu.2013.00455.

67. Medyouf H, Mossner M, Jann JC, Nolte F, Raffel S, Herrmann C, et al. Myelodysplastic cells in patients reprogram mesenchymal stromal cells to establish a transplantable stem cell niche disease unit. Cell Stem Cell. 2014;14(6):824-837. doi:10.1016/j.stem.2014.02.014.

68. Chen X, Eksioglu EA, Zhou J, Zhang L, Djeu J, Fortenbery $\mathrm{N}$, et al. Induction of myelodysplasia by myeloid-derived suppressor cells. J Clin Invest. 2013;123(11):4595-4611. doi:10.1172//CI67580.

69. Daver N, Boddu P, Garcia-Manero G, Yadav SS, Sharma P, Allison J, et al. Hypomethylating agents in combination with immune checkpoint inhibitors in acute myeloid leukemia and myelodysplastic syndromes. Leukemia. 2018;32(5):1094-1105. doi:10.1038/s41375-018-0070-8.

70. Borate U, Esteve J, Porkka K, Knapper S, Vey N, Scholl S, et al. Phase Ib study of the anti-TIM-3 antibody MBG453 in combination with Decitabine in patients with high-risk myelodysplastic syndrome (MDS) and acute myeloid leukemia (AML). ASH 2019, O570. doi: https://doi.org/10.1182/ blood-2019-128178.

71. Russ A, Hua AB, Montfort WR, Rahman B, Riaz IB, Khalid MU, et al. Blocking "don't eat me" signal of CD47-SIRPa in hematological malignancies, an in-depth review. Blood Rev. 2018;32(6):480-489. doi:10.1016/j.blre.2018.04.005.

72. Liu J, Wang L, Zhao F, Tseng S, Narayanan C, Shura L, et al. Pre-clinical development of a humanized anti-CD47 antibody with anti-cancer therapeutic potential. PLoS One. 2015;10(9):e0137345. Published 2015 Sep 21. doi:10.1371/ journal.pone.0137345.

73. Sallman DA, Asch AS, Al Malki MM, Lee DJ, Donnellan WB, Marcucci G, et al. The first-in-class anti-CD47 anti- body Magrolimab (5F9) in combination with Azacitidine is effective in MDS and AML patients: Ongoing Phase $1 \mathrm{~b}$ results. Blood 2019; 134 (Supplement_1): 569. doi: https://doi. org/10.1182/blood-2019-126271.

74. Konopleva M, Letai A. BCL-2 inhibition in AML: an unexpected bonus?. Blood. 2018;132(10):1007-1012. doi:10.1182/blood-2018-03-828269.

75. DiNardo CD, Pratz KW, Letai A, Jonas BA, Wei AH, Thirman $M$, et al. Safety and preliminary efficacy of venetoclax with decitabine or azacitidine in elderly patients with previously untreated acute myeloid leukaemia: a non-randomised, open-label, phase 1b study. Lancet Oncol. 2018;19(2):216228. doi:10.1016/S1470-2045(18)30010-X.

76. Slape CI, Saw J, Jowett JB, Aplan PD, Strasser A, Jane $\mathrm{SM}$, et al. Inhibition of apoptosis by BCL2 prevents leukemic transformation of a murine myelodysplastic syndrome. Blood. 2012;120(12):2475-2483. doi:10.1182/ blood-2012-05-430736.

77. DiNardo CD, Rausch CR, Benton C, Kadia T, Jain N, Pemmaraju N, et al. Clinical experience with the BCL2-inhibitor venetoclax in combination therapy for relapsed and refractory acute myeloid leukemia and related myeloid malignancies. Am J Hematol. 2018;93(3):401-407. doi:10.1002/ ajh.25000.

78. Ball BJ, Famulare CA, Stein EM, Tallman MS, Derkach A, Roshal M, et al. Venetoclax and hypomethylating agents (HMAs) induce high response rates in MDS, including patients after HMA therapy failure. Blood Adv. 2020;4(13):28662870. doi:10.1182/bloodadvances.2020001482.

79. Ingham PW, Nakano Y, Seger C. Mechanisms and functions of Hedgehog signalling across the metazoa. Nat Rev Genet. 2011;12(6):393-406. doi:10.1038/nrg2984.

80. Savona MR, Pollyea DA, Stock W, Oehler VG, Schroeder MA, Lancet J, et al. Phase Ib study of Glasdegib, a hedgehog pathway inhibitor, in combination with standard chemotherapy in patients with AML or high-risk MDS. Clin Cancer Res. 2018;24(10):2294-2303. doi:10.1158/1078-0432. CCR-17-2824.

81. Cortes JE, Douglas Smith B, Wang ES, Merchant A, Oehler VG, Arellano M, et al. Glasdegib in combination with cytarabine and daunorubicin in patients with AML or high-risk MDS: Phase 2 study results. Am J Hematol. 2018;93(11):1301-1310. doi:10.1002/ajh.25238.

82. Cortes JE, Heidel FH, Hellmann A, Fiedler W, Smith BD, Robak T, et al. Randomized comparison of low dose cytarabine with or without glasdegib in patients with newly diagnosed acute myeloid leukemia or high-risk myelodysplastic syndrome. Leukemia. 2019;33(2):379-389. doi:10.1038/ s41375-018-0312-9.

83. Chaudhry P, Singh M, Triche TJ, Guzman M, Merchant AA. GLI3 repressor determines Hedgehog pathway activation and is required for response to SMO antagonist glasdegib in AML. Blood. 2017;129(26):3465-3475. doi:10.1182/ blood-2016-05-718585. 
84. Chowdhury R, Yeoh KK, Tian YM, Hillringhaus L, Bagg EA, Rose NR, et al. The oncometabolite 2-hydroxyglutarate inhibits histone lysine demethylases. EMBO Rep. 2011;12(5):463-469. doi:10.1038/embor.2011.43.

85. Xu W, Yang H, Liu Y, Yang Y, Wang P, Kim SH, et al. Oncometabolite 2-hydroxyglutarate is a competitive inhibitor of a-ketoglutarate-dependent dioxygenases. Cancer Cell. 2011;19(1):17-30. doi:10.1016/j.ccr.2010.12.014.

86. Stein EM, Fathi AT, DiNardo CD, Pollyea DA, Swords RT, Roboz GJ, et al. Enasidenib (AG-221), a potent oral inhibitor of mutant isocitrate dehydrogenase 2(IDH2) enzyme, induces hematologic responses in patients with myelodysplastic syndromes (MDS). Blood. 2016;128(22). Abstract 343. doi: 10.1182/blood.V128.22.343.343.

87. Roboz GJ, DiNardo CD, Stein EM, de Botton S, Mims AS, Prince GT, et al. Ivosidenib induces deep durable remissions in patients with newly diagnosed IDH1-mutant acute myeloid leukemia. Blood 2020; 135 (7): 463-471. doi: 10.1182/ blood.2019002140.

88. Chun AW, Cosenza SC, Taft DR, Maniar M. Preclinical pharmacokinetics and in vitro activity of ON 01910.Na, a novel anti-cancer agent. Cancer Chemother Pharmacol. 2009;65(1):177-186. doi:10.1007/s00280-009-1022-9.

89. Garcia-Manero G, Fenaux P, Al-Kali A, Baer MR, Sekeres MA, Roboz GJ, et al. Rigosertib versus best supportive care for patients with high-risk myelodysplastic syndromes after failure of hypomethylating drugs (ONTIME): a randomised, controlled, phase 3 trial. Lancet Oncol. 2016;17(4):496-508. doi:10.1016/S1470-2045(16)00009-7.

90. Navada SC, Gacia-Manero G, Atallah EL, Rajeh MN, Shammo JM, Griffith EA, et al. Phase 2 expansion study of oral rigosertib combined with azacitidine (AZA) in patients (Pts) with higher-risk (HR) myelodysplastic syndromes (MDS): efficacy and safety results in HMA treatment naïve \& relapsed (Rel)/refractory (Ref) patients [abstract]. Blood. 2018;132. Abstract 230. doi: 10.1182/blood-2018-99-119259.

91. Stone RM, Mandrekar SJ, Sanford BL, Laumann K, Geyer S, Bloomfield CD, et al. Midostaurin plus chemotherapy for acute myeloid leukemia with a FLT3 mutation. N Engl J Med. 2017;377(5):454-464. doi:10.1056/NEJMoa1614359.

92. Strati P, Kantarjian H, Ravandi F, Nazha A, Borthakur G, Daver N, et al. Phase I/II trial of the combination of midostaurin (PKC412) and 5-azacytidine for patients with acute myeloid leukemia and myelodysplastic syndrome. Am J Hematol. 2015;90(4):276-281. doi:10.1002/ajh.23924.

93. Pratz KW, Cherry M, Altman JK, Cooper B, Cruz JC, Jurcic JG, et al. Updated results from a Phase 1 Study of Gilteritinib in combination with induction and consolidation chemotherapy in subjects with newly diagnosed acute myeloid leukemia (AML). Blood 2018; 132 (Supplement 1): 564. doi: 10.1182/blood-2018-99-110975.

94. Altman JK, Foran JM, Pratz KW, Trone D, Cortes JE, Tallman MS. Phase 1 study of quizartinib in combination with induction and consolidation chemotherapy in patients with newly diagnosed acute myeloid leukemia. Am J Hematol. 2018;93(2):213-221. doi:10.1002/ajh.24974.
95. Stevens BM, Zhang W, Pollyea DA, Winters A, Gutman J, Smith C, et al. CD123 CAR T cells for the treatment of myelodysplastic syndrome. Exp Hematol. 2019;74:52-63.e3. doi:10.1016/j.exphem.2019.05.002.

96. Roeker LE, Dreger P, Brown JR, Lahoud OB, Eyre TA, Brander DM, et al. Allogeneic stem cell transplantation for chronic lymphocytic leukemia in the era of novel agents. Blood Adv. 2020;4(16):3977-3989. doi:10.1182/bloodadvances.2020001956.

97. Paul S, Zahurak M, Luznik L, Ambinder RF, Fuchs EJ, Bolaños-Meade J, et al. Non-myeloablative allogeneic transplantation with post-transplant cyclophosphamide after immune checkpoint inhibition for classic Hodgkin lymphoma: A retrospective cohort study. Biol Blood Marrow Transplant. 2020;26(9):1679-1688. doi:10.1016/j.bbmt.2020.06.012.

98. Morozova EV, Vlasova YuYu, Barabanshchikova MV, et al. Chronic myeloid leukemia: role of allogeneic hematopoietic stem cell transplantation in the era of tyrosine kinase inhibitors. Clinical Oncohematology. 2020;13(2):193-198 (In Russian). DOI: 10.21320/2500-2139-2020-13-2-193-198.

99. Oran B, Garcia-Manero G, Saliba RM, Alatrash G, Jabbour EJ, Popat U, et al. Post Allogeneic Stem Cell Transplant (SCT) Cyclophosphamide improves progression free survival (PFS) in pts with AML/MDS treated with CTLA-4 or PD-1 blockade prior to SCT. Blood 2018; 132 (Supplement 1): 483. https://doi.org/10.1182/blood-2018-99-115382. 


\section{Новые опции лечения пациентов}

с миелодиспластическим синдромом:

обзор литературы и результаты одноцентрового исследования

\section{Елена В. Морозова, Николай Ю. Цветков, Ирина О. Туртанова, Иван С. Моисеев}

НИИ детской онкологии, гематологии и трансплантологии им. Р. М. Горбачевой, Первый Санкт-Петербургский государственный медицинский университет им. акад. И. П. Павлова, Санкт-Петербург, Россия

\section{Резюме}

Миелодиспластический синдром (МДС) - это гетерогенная группа клональных заболеваний, в основе которой находится поражение гемопоэтической стволовой клетки, как следствие наследственной предрасположенности, а также соматических мутаций различных генов и/или эпигенетической регуляции, в том числе индуцированных нарушением микроокружения и нарушениями в иммунной системе противоопухолевого надзора.

В обзоре освещаются долгосрочные результаты существующих методов лечения МДС, а также эффективность новых препаратов, находящихся на различных стадиях клинических испытаний, включая ингибиторы сигнальных путей, ингибиторы контрольных точек, антагонисты трансформирующего ростового фактора бета. Характеризуется взаимосвязь новых методов терапии с патогенетическими основами МДС.

\section{Ключевые слова}

Миелодиспластический синдром, терапия, ингибиторы контрольных точек, луспатерцепт, гласдегиб, венетоклакс, IDH ингибиторы. 